\title{
Fisheries management: from linear to collaborative science-policy interface
}

\author{
R. Aps ${ }^{1}$, M. Fetissov ${ }^{1}$, N. Holmgren ${ }^{2}$, N. Norrström ${ }^{2} \&$ S. Kuikka ${ }^{3}$ \\ ${ }^{1}$ Estonian Marine Institute, University of Tartu, Tallinn, Estonia \\ ${ }^{2}$ University of Skövde, Skövde, Sweden \\ ${ }^{3}$ University of Helsinki, Helsinki, Finland
}

\begin{abstract}
The context of fisheries management, according to recent studies, tends to be complex, uncertain and controversial and it cannot be adequately addressed based on work done within the "linear" science-policy interface (SPI). It is believed that moving towards a more participatory and "collaborative" SPI model would favourimplementation of more efficient economic incentives to reduce the fishing fleet capacity and bring the actual fishing mortality closer to the levels considered to be sustainable. Focusing the participatory research basically on fish biology and fish stock assessment seems to be too narrow while, on the other hand, it does not embrace many other important issues of contemporary fisheries management. It is suggested that further involvement of stakeholders into the full-scale bio-economic modelling based participatory research would contribute to better understanding of the dynamics of humannatural interface concerned and, consequently, would improve the consensus between different interests.
\end{abstract}

Keywords: fisheries management, science-policy interface, participatory research.

\section{Introduction}

The science-policy interface (SPI) is defined [1] as "...institutional arrangements that reflect cognitive models and provide normative structures, rights, rules and procedures that define and enable the social practice of linking scientific and policymaking processes. They assign roles to scientists, policy-makers, other relevant stakeholders and knowledge holders and help guide their interactions 
according to specific principles and purposes. If both the activities of making science, viewed as the systematic pursuit of knowledge, and of making policy (politics), viewed as the process of bargaining, negotiation and compromise are influenced by institutional structures, then, by extension, their interactions should also be understood in institutional terms".

It is stated [1] that the linear cognitive model of SPI is based "...on belief in a clear distinction between "objective knowledge" and "subjective values" and presumes politically neutral scientists "speak truth to power" providing objective representations of reality, upon which decision makers take rational decisions subsequently implemented by administrators". The authors continue: "While the linear model of science-policy interrelations has served both science and politics well over the years, it is suitable only in the simplest of decision contexts where the issue in question can be adequately captured using a single perspective or description and by a standard model providing a satisfactory description or general solution through routine operations. In contrast, international environmental governance tends to be complex, uncertain and controversial, entailing a multiplicity of legitimate perspectives and discourses laden with conflicts over facts, interests and values. These cannot be adequately represented using a single perspective or description or by a single standard model or general solution".

As a result of reassessing the interrelations of science and policy in the context of complexity and uncertainty, a number of alternatives to the linear model of SPI have emerged in recent years. Koetz et al. [1], referring to Pielke [2], suggests that “...two features common to all SPI alternative models are: (1) questioning the presumption that there is always a clear separation between facts and value and (2) reference to some form of "stakeholder model" that presumes complex interrelations between science and policy and recommends deliberation, collaborative evaluations and critiques that reach across epistemic frameworks".

Forsyth [3] argues that "perhaps the most useful and all-encompassing conceptual device for explaining the mutual evolution of science and politics is coproduction". This concept is defined by Jasanoff [4] as the "simultaneous production of knowledge and social order" and it is explaining how scientific knowledge both embeds and is embedded in social identities, institutions, representations and discourses. According to Forsyth [3], coproduction “... refers to processes by which knowledge, including scientific knowledge, is framed, collected, and disseminated through social interaction and change". Furthermore, co-production of science and policy is considered to be an important element in production of usable science [5].

A boundary organization is an increasingly common phoneme. According to Guston [6], boundary organizations are referred to those social arrangements, networks and institutions that increasingly mediate between the institutions of science and of politics. Miller [7] argues that the boundary organizations need to be able to manage hybrids - to put scientific and political elements together, take them apart, establish and maintain boundaries between different forms of life, and coordinate activities taking place in multiple domains. It is further stated that by helping to manage hybrids, boundary organizations contribute to the 
maintenance of a productive tension between science and politics. However, they appear to need the approval of science for credibility of their knowledge claims as well as the approval of political institutions for legitimacy of their policy orientations.

Forsyth [3] draws attention to hybridization and argues that "researchers of the social construction of environmental "facts" have used this term to refer to the (often historical) processes by which social-natural objects become entwined through social discourse, and henceforth become accepted as objects".

This paper attempts to discuss the process of evolving the fisheries management from "orthodox" science based work within the "linear" SPI towards a more "collaborative" SPI enabling further involvement of stakeholders into the full-scale bio-economic modelling based participatory research.

\section{The Common Fisheries Policy (CFP) and the objective of fisheries management}

The Common Fisheries Policy inter alia is a scheme for sharing a common resource among countries. The Total Allowable Catches (TAC's) are simple to deal with in that context and therefore used as the basis in international management while effort or capacity is more difficult to work with. Effort regulations may have control and enforcement advantages. However, choosing a management measure without addressing the fundamental economic conflict leads to high management costs and in practice have proven impossible to enforce.

According to generally accepted definition, the Maximum Sustainable Yield (MSY) is the largest average equilibrium catch or yield that can continuously be taken from a stock under existing environmental conditions. For the "orthodox" fisheries science, the MSY has been, and still remains a key paradigm in fisheries management representing the traditional key objective: removals should be as large as possible but nevertheless sustainable in the long run.

Already in 1976, the International Council for the Exploration of the Sea (ICES) ad hoc working group was devoted to critical analysis of the significance of the MSY concept and the uses and interpretations which have been made of it [8]. The main finding was that the simple MSY concept as used up to those days does not incorporate the entire vital processes particular to fish resources. It was stated that various conditional qualifications must be added if it is to serve as an adequate and generally acceptable management objective. The most important of these qualifications concerns the exploitation pattern and relationship between spawning stock and recruitment.

Commenting on the MSY concept in general, Larkin [9] argues that "The approach must be anthropocentric. It is a contradiction in terms to speak of biological objectives of fisheries management. Much more logical is to speak of biological constraints to management ... The real questions are: what should be the biological constraints and what should be the social objectives". In other words, biological status of fishery resources should be considered rather as constraint and not as an objective for fisheries management. 
Sissenwine and Symes [10] say that "Somewhat unwillingly, as a result of decisions made at the World Summit on Sustainable Development (WSSD), [European Commission's] DG Fish has been obliged to adopt the concept of maximum sustainable yield (MSY) as a strategic goal for the management of Europe's fisheries."

\section{3 "Orthodox" science}

The ICES advice is a boundary function between management and science. The advice is driven by management/policy, e.g. the first ICES - EC arrangement (1987) states "The Commission of the European Communities... shall have the right to ask the International Council for the Exploration of the Sea ....for scientific advice on fisheries resources management and related matters, which the Council shall to the extent possible provide". The "Memorandum of Understanding" and the "Letter of Agreement" form the formal basis for the ICES regulatory science-policy co-production process. On the science side, the ICES advisory process claims to be based on the best available regulatory science, the advice is generated in accordance to working arrangements, working relationships and cooperation that have been in place on all levels of the ICES network since its inauguration and were taken as integral parts of ICES' regular work. ICES advisory science, however, until recently has been limited to consideration of the impact on the marine ecosystem while socio-economic considerations have been outside ICES remit. This division was discussed already in 1976 at the ICES ad hoc working group on the biological basis for fisheries management (Charlottenlund, January 1976) and it was concluded that: "Because biologically-based objectives such as highest physical yield from a resource has been thought to represent a more generally acceptable aims of fishery management than for instance economic objectives, fishery scientists have played a primary role in formulating and promoting objectives for resource management" [8].

Until recently, the science provided by the ICES rather well matched the term "orthodox science" defined by Forsyth [3] as "...scientific practices that characterize much basic research in ecology involving principles loosely labelled as "positivism". These practices may be called "orthodox" because they date from early thinking about science and scientific practice that sought to establish scientific knowledge as a privileged source of accuracy and political neutrality. Orthodox science, in this context, may be characterized by three key tenets: the mechanism of inference from samples; the self-regulation of findings and research by scientists; and an underlying belief in the ability of science to indicate reality in an accurate and unbiased way". It is stated further that debates within non-equilibrium ecology have had immense implications for environmental explanation and orthodox science aiming for "laws" of nature while indicating, again, that the underlying events and processes occurring within ecological systems are far more complex than commonly suggested by initial explanations. 


\section{Participatory research: step towards collaborative science-policy interface}

Mackinson et al. [11] argue that engaging stakeholders in research and decisionmaking on European marine issues is endorsed at high levels because the agreement of stakeholders is believed to be essential for any management plan to succeed. Authors propose the framework for enabling participation in research and governance of fisheries and the marine environment (Figure 1).

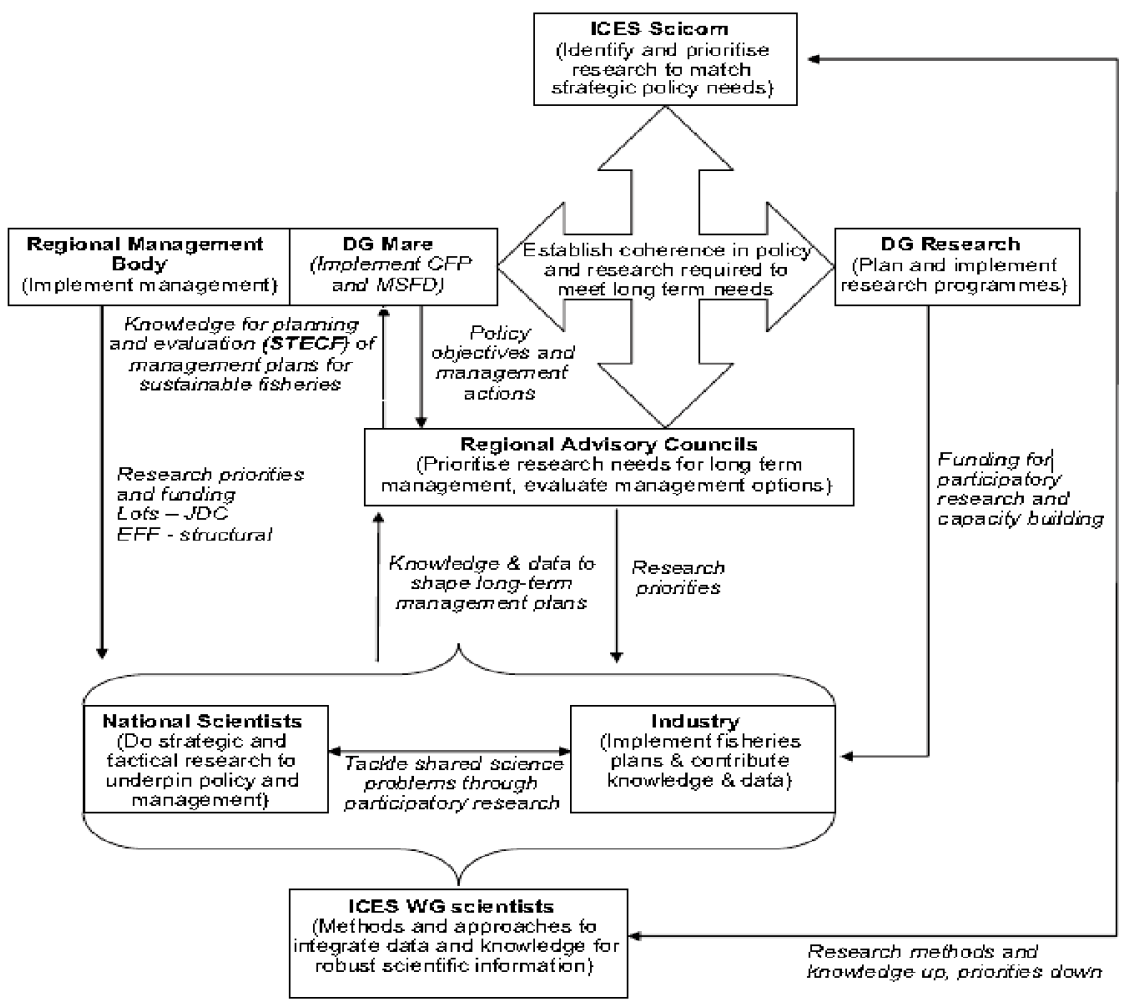

Figure 1: Framework for enabling stakeholder participation in research and governance of fisheries and the marine environment [11].

The suggested framework represents the network of interacting institutions for enabling stakeholder participation in research and governance of fisheries and the marine environment. The key institutions listed are: EC Commission (DG Mare and DG Research), International Council for the Exploration of the Sea, (ICES) that embrace the national scientists, Regional Advisory Councils (2/3 industry and $1 / 3$ other interest groups affected by CFP).

Mackinson et al. [11] define the "...participatory research as a means of active engagement, and can be seen as an alternative cultural approach to doing science. It means individuals and organizations working together, with both 
scientists and stakeholders being involved in all stages of the research planning and delivery. Participation may take a variety of forms and change over time depending on the situation and need. This can range from consultation to cooperation to collaboration, the level of participation being determined principally by scale and nature of the issues and the contribution that stakeholders are willing and able to do effectively". It is further specified that the reasoning is that including fishers' knowledge and know-how will enhance scientific understanding and improve the quality of data required for scientific assessments of fish stocks.

\section{Widening focus of participatory research}

Focusing the participatory research primarily on fish biology and fish stock assessments seems to be too narrow while, on the other hand, it does not embrace many other important issues of contemporary fisheries management. Hannesson [12] argues that fishers fish for money and will therefore fish at an effort level that optimises their earnings. Restricting fishing through input or output management measures does not change this fundamental mechanism. Classical management measures (TACs, effort limitations, closed areas, etc) are all faced with the conflict between the optimal fishing level seen from the industry point of view and that seen from a sustainability and environmental perspective.

The fishing industry is exploiting fishery resources to generate a profit. Provided that fishing industry is using the fishery resources in a sustainable manner, the net revenue itself depends on an array of economic conditions such as cost of fishing operations, market demand, availability of subsidies, interest rate for capital etc. Governments sometimes prioritize social objectives such as maintaining employment in coastal communities over economic objectives. The relevant perspective depends on the society, the fishery and the habitats which the fisheries impact.

In either case, the state and the dynamics of fishery resources are the main constraints for economic expansion of the fisheries industry, or for achieving desired social conditions, and it is these constraints that should be observed in order to keep the fisheries resources in a state where the social and economic objectives are likely to be highly obtainable.

Hilborn [13] argues that managing fisheries is managing people and in addition to the task of improving the quality of fish stock assessment, there are many other and maybe more critical tasks to focus the participatory research on: "The current major problems with many fisheries include poor economic performance, loss of yield due to overfishing, by-catch of non-target fisheries, poor data, fishing impacts on marine ecosystems and habitat and poor compliance with regulations". These would be the topics for participatory research with the fishers, biologists, economists, sociologists, and political scientists all involved.

Economic and ecological components of fishery systems interact reciprocally and form complex feedback loops. The dynamics of the fishery systems are 
influenced by many factors, including government policies and contextual factors in which local processes are shaped by larger-scale and ultimately globalscale processes. Therefore, it seems to be reasonable to widen the focus of the participatory research from basically fish stock assessment problems to the whole complex dynamics of the fishery systems. The achievements of contemporary bio-economic modelling of the fishery systems are providing the usable framework for that.

For example, the FISHRENT model [14] comprises of six modules, each focusing on a different aspect of the functioning of the fishery system: biology (stocks), economy (costs, earnings and profits), policy (TACs, effort and access fees), behaviour (investments), prices (fish and fuel) and an interface linking the modules together (Figure 2).

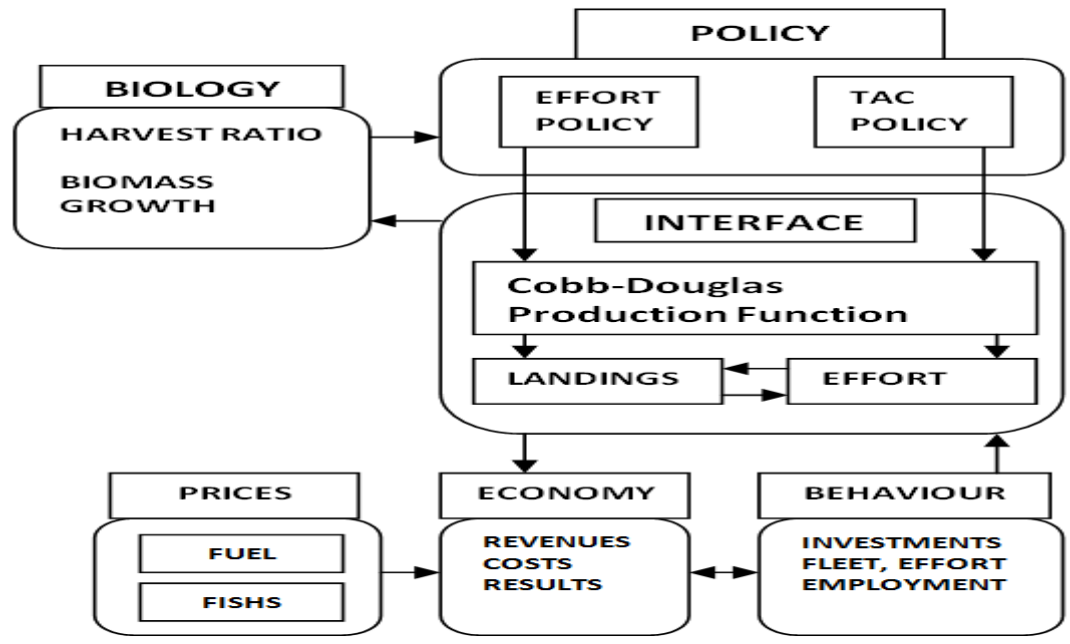

Figure 2: $\quad$ Principal architecture of the FISHRENT bio-economic model [14].

It is stated [14] that the FISHRENT bio-economic model has been built in Excel, which makes it accessible for most users. While the model is continually further developed, it has been used in new applications and even translated to other software. Authors also argue that the model contains a number of important assumptions, which remain to be tested empirically and, therefore, the model presents a challenging agenda for empirical research. It may be added that e.g. the FISHRENT model could represent the challenging agenda also for the participatory research into the dynamics of fishery systems.

\section{Baltic Sea fisheries management}

\subsection{Baltic Sea Regional Advisory Council: from integrating knowledge to balancing the stakeholders' interests}

The Baltic Sea Regional Advisory Council (BS RAC) was established with the Council Decision (EC) 256/2004 with the intention to increase the participation of stakeholders in the fisheries management decision-making process. 
The boundary work of the BS RAC in balancing stakeholder's interests in transformation of science-based advice into agreed management recommendations is considered to be an important element in setting the Baltic TACs [15]. BS RAC is serving as a platform for the fishing industry and the non-governmental organizations to negotiate the recommendations to the European Commission on fisheries issues under the CFP. Scientific advice produced and delivered by ICES is used as a biological background for deliberations. BS RAC acts as 1) a facilitator of dialogue between the fishing industry, scientists and decision makers to encourage research agendas that reflect the interests and needs of fishing industry, 2) a translator of scientific information into fishery-specific practical language, and 3) a facilitator of communication among scientists, fishing industry, non-governmental organizations, and political officials, engaged in formal and informal efforts to clarify both technical requirements and value choices, and helping negotiate compromise settlements among stakeholders.

Linke et al. [16] state that a non-consensual way of formulating recommendations on fishing advice (TACs) became a central feature of the BSRAC over the years while the environmental NGOs complain that the fishing industry interests are often overrepresented and dominate the RAC proposals. Authors add that "It is the BSRAC's objective to include different forms of knowledge through the inclusion of different stakeholders, and thus to fulfil a task of evaluating scientific advice that is established on certain propositions. However, because of the mentioned oppositions in how to interpret ICES' scientific input due to individual stakeholder agendas, this task seems not to be fulfilled".

Actually, the problem seems to be caused not only by the failure to include different forms of knowledge through the inclusion of different stakeholders into the negotiation process. BS RAC members, as maximizers of economic value, often experience difficulties in balancing their socio-economic interests in translation of science advice into agreed management recommendations. Therefore, it seems to be explicitly important to also include the socio-economic interests of stakeholders into the BS RAC' deliberations. It is also believed that further involvement of stakeholders into the full-scale bio-economic modelling based participatory research would contribute to a better understanding of dynamics of human-natural interface concerned and, consequently, would improve the consensus between different interests.

\subsection{Central Baltic Sea herring fishery management: the key demand is for more collaborative science-policy interface}

The Bayesian Belief Networks (BBNs) developed to communicate the major sources of uncertainty related to the management of the Central Baltic Sea herring fisheries [17] are amended and used in this study. The BBN network (Figure 3) represents two yearly cycles of fishery activities and contains two information variables: 1) "FLEET_CAPACITY" (fishing fleet capacity is balanced/not balanced with the fishery resources available), 2) "PUBLIC_PRESSURE" (reasoning in support of sustainable fishing - 
strong/weak), and one hypothesis variable -"HARVEST" (fishing mortality is less or equal to the $\mathrm{F}_{\mathrm{MSY}}$ /fishing mortality exceeds the $\mathrm{F}_{\mathrm{MSY}}$ ). ( $\mathrm{F}_{\mathrm{MSY}}$ - fishing mortality that corresponds to the Maximum Sustainable Yield (MSY)) The rest are intermediate nodes ("CONTROL_ENFORCEMENT" and "TAC DECISION" that help propagate evidence from the information variables to the hypothesis variable. The BBN network node "SCIENCE POLICY_INTERFACE" can be in state "linear" or "collaborative". It is assumed that the work carried out within the recent "linear" SPI is not sufficiently responsive to the conditions and needs of the policy process, and therefore is partly responsible for the fishing fleet overcapacity (overcapitalization), weak public reasoning in support of sustainable fishing and, consequently, fishing at the level believed to be unsustainable (Figure 3).

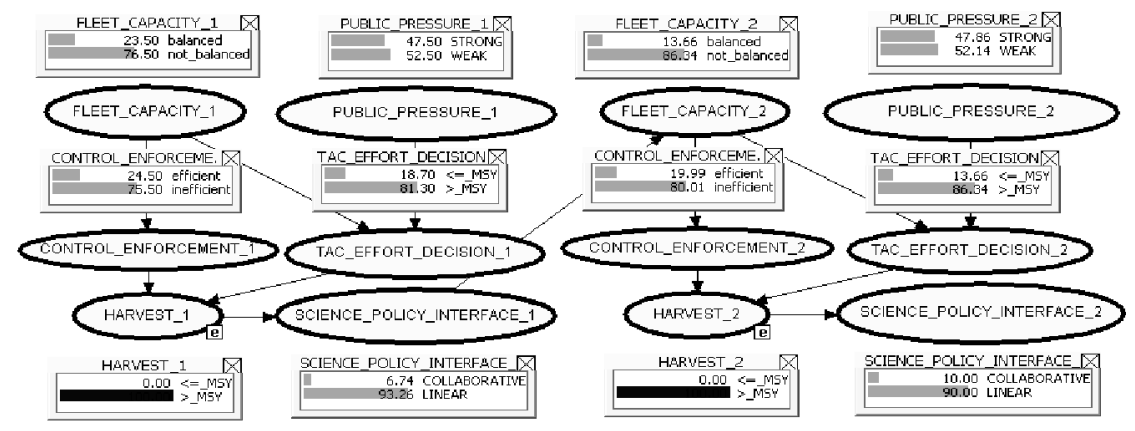

Figure 3: $\quad \mathrm{BBN}$ representing the state of the knowledge for the current status of the Central Baltic Sea herring fishery management according to the work carried out within the recent "linear" SPI.

It is further assumed that the work carried out within the more "collaborative" SPI would favourimplementation of more efficient economic incentives to reduce the fishing fleet capacity and bring the actual fishing mortality closer to the $\mathrm{F}_{\mathrm{MSY}}$ value (Figure 4).

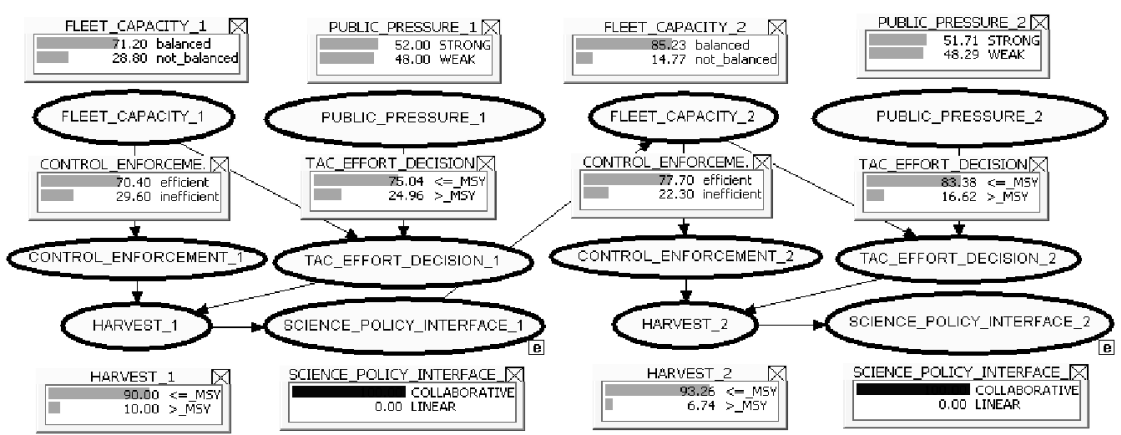

Figure 4: $\quad$ BBN representing the state of the knowledge for the expected status of the Central Baltic Sea herring fishery management according to the work carried out within the more "collaborative" SPI. 
The EU Green Paper [18] describes the issue as follows: "Overall poor performance [of fishing industry] is due to chronic overcapacity of which overfishing is both a cause and a consequence: fleets have the power to fish much more than can safely be removed without jeopardizing the future productivity of stocks. Capacity reductions in recent years have not been sufficient to break this vicious circle." Matching fishing effort to available resources is considered to be an important precondition for sustainable use of fishery resources and removal of excess capacity is regarded, therefore, as an important objective.

In addressing this issue, the European Commission [19] states that fleet overcapacity is as much an economic as a conservation issue being clearly conducive to over-fishing and economic underperformance. The conclusion was made that imbalance between excess effort and available resources needs to be addressed as a matter of urgency if the Community fishing industry is to regain profitability, and to reverse this downward spiral, leading to lower yields and revenues for fishers. As a result, the fishing effort must return to levels compatible with the higher and sustainable fishing yields.

Actually, according to the European Court of Auditors [20] the current system of giving responsibility for managing capacity to the Member States and focusing Community action on fishing effort limitation does not include any measure of constraint which could lead to a reduction in this overcapacity, and the problem of overcapacity therefore seems likely to persist in years to come and will continue to have a bearing on compliance with Common Fisheries Policy rules in general, and on setting negotiated TACs and quotas in particular.

\section{Conclusions}

According to recent studies the context of fisheries management tends to be complex, uncertain and controversial $[11,16]$, and it cannot be adequately addressed based on work done within the "linear" science-policy interface (SPI). It is believed that moving towards a more participatory and "collaborative" SPI model would favour the implementation of more efficient economic incentives to reduce the fishing fleet capacity and bring the actual fishing mortality closer to the levels considered to be sustainable. It is expected that work done within the more "collaborative" SPI would facilitate the eradication of the current major problems with many fisheries that include, as indicated by contemporary studies [13], poor economic performance, loss of yield due to overfishing, by-catch of non-target fishes, poor data, fishing impact on the marine ecosystems and habitat and poor compliance with regulations.

Focusing the participatory research primarily on fish biology and fish stock assessment seems to be too narrow while, on the other hand, does not embrace many other important issues of contemporary fisheries management. It is suggested that further involvement of stakeholders into the full-scale bioeconomic modelling based participatory research would contribute to better understanding on dynamics of human-natural interface concerned and, consequently, would improve the consensus between different interests. 


\section{Acknowledgements}

This study was supported by the Estonian Science Foundation grant No.7609, Estonian target financing program SF0180104s08, by the Baltic Organizations Network for Funding Science EEIG (BONUS+) Project IBAM "Integrated Bayesian risk analysis of ecosystem management - Gulf of Finland as a case study", and by the EU 7FP Project GAP2 "Bridging the gap between science, stakeholders and policy makers (Phase 2 - Integration of evidence-based knowledge and its application to science and management of fisheries and the marine environment)".

\section{References}

[1] Koetz, T., Farrell, K.N. \& Bridgewater, P., Building better science-policy interfaces for international environmental governance: assessing potential within the Intergovernmental Platform for Biodiversity and Ecosystem Services. Int. Environ. Agreements. DOI 10.1007/s10784-011-9152-z, 2011.

[2] Pielke, R.A. Jr., The honest broker: making sense of science in policy and politics. Cambridge University Press, New York, 188 pp. 2007.

[3] Forsyth, T., Critical political ecology: the politics of environmental science. Routledge, London \& New York, 320 pp., 2008.

[4] Jasanoff, S., States of knowledge: the co-production of science and social order. Routledge, London \& New York, 317 pp., 2004.

[5] Lemos, M.C. \& Morehouse B.J., The co-production of science and policy in climate assessments. Global Environ. Change, 15(1), pp. 57-68, 2005.

[6] Guston, D.H., Boundary organizations in environmental policy and science: an introduction. Science, Technology \& Human Values, 26(4), pp. 399-408, 2001.

[7] Miller, C., Hybrid management: boundary organizations, science policy, and environmental governance in the climate regime. Science, Technology \& Human Values, 26(4), pp. 478-500, 2001.

[8] IBSFC. International Baltic Sea Fisheries Commission: Proceedings of the Second Session. Warsaw, September 27-October 11976.154 pp., 1976.

[9] Larkin, P.A., Comments on the workshop presentations. In W.S. Wooster Ed. Fishery Science and Management: Objectives and Limitations. Lecture Notes on Coastal and Estuarine Studies.Vo1 28, Springer-Verlag, New York, pp. 287-289, 1988.

[10] Sissenwine, M. \& Symes D., Reflections on the Common Fisheries Policy. Report to the General Directorate for Fisheries and Maritime Affairs of the European Commission, 75 pp., 2007.

[11] Mackinson, S., Wilson, D.C., Galiay, P. \& Deas, B., Engaging stakeholders in fisheries and marine research. Marine Policy, 35, pp.18-24, 2011.

[12] Hannesson, R., Bioeconomic Analysis of Fisheries. Fishing News Books, FAO, Rome, 138 pp., 1993. 
[13] Hilborn, R., Managing fisheries is managing people: what has been learned? Fish and Fisheries, 8, pp. 285-296, 2007.

[14] Salz, P., Buisman, E., Frost, H., Accadia, P., Prellezo, R. \& Soma, K., FISHRENT: bio-economic simulation and optimisation model for fisheries. LEI Report 2011-024, 74 pp., 2011.

[15] Aps, R., Fetissov, M., Kell, L. \& Lassen, H., Baltic Sea Regional Advisory Council as a hybrid management framework for sustainable fisheries, pp. 163-172. In: Ecosystems and sustainable development VII, Eds. Brebbia C.A., Tiezzi, E. WIT PRESS, Southampton, Boston, 2009.

[16] Linke, S., Dreyer, M. \& Sellke, S., The Regional Advisory Councils: What is their potential to incorporate stakeholder knowledge into fisheries governance? Ambio, 40, pp. 133-143. 2011.

[17] Aps, R., Fetissov, M., Holmgren, N., Norrström, N. \& Kuikka, S., Central Baltic Sea herring: effect of environmental trends and fishery management. In: Y. Villacampa, C.A. Brebbia (Eds.). Ecosystems and Sustainable Development VIII, WIT Press Southampton, Boston, pp. 69-80, 2011.

[18] EC. Reform of the Common Fisheries Policy: Green Paper. European Commission. 24 pp., 2009.

[19] Anon. Communication from the Commission to the Council and the European Parliament on improving the economic situation in the fishing industry. COM (2006) 103 final, 2006.

[20] Anon. The European Court of Auditors' Special Report No 7/2007 on the control, inspection and sanction systems relating to the rules on conservation of Community fisheries resources, 2007, $71 \mathrm{pp}$. 